\title{
The effect of lincomycin on exoprotein production by Vibrio cholerae
}

\author{
D. B. YOUNG* and D. A. BROADBENT
}

Department of Medical Microbiology, London School of Hygiene and Tropical Medicine, Keppel Street, London WC1E 7 HT

\begin{abstract}
Summary. Lincomycin has a differential effect on exoprotein production by Vibrio cholerae. The production of some proteins, such as cholera toxin and deoxyribonuclease, is stimulated by low concentrations of the drug while production of other proteins, such as protease and alkaline phosphatase, is unaffected. Possible mechanisms of the lincomycin effect are discussed.
\end{abstract}

\section{Introduction}

Elucidation of the structure and mode of action of cholera toxin has improved the understanding of the pathogenicity of Vibrio cholerae (Holmgren, 1980). Less is known about the way in which toxin production is related to the overall physiology of the bacterium. Toxin-deficient mutants have been reported to show some growth defects (Honda and Finkelstein, 1979) and a role in metabolic regulation has been proposed for a membrane-bound form of the toxin (Fernandes et al., 1979).

Cholera toxin is unusual among bacterial secretory proteins so far investigated in that it is synthesised on free, as distinct from membranebound, polysomes (Nichols et al., 1980). After synthesis, toxin must be transported through both inner and outer membranes and release of toxin by treatment of cells with sodium deoxycholate (Fernandes and Smith, 1977; Fernandes and Bayer, 1977) or polymyxin B (Evans et al., 1974; Levner et al., 1980) suggests the presence of a membranebound, or periplasmic, pool in addition to the extracellular toxin. Production of cholera toxin and the related heat-labile toxin of enterotoxigenic Escherichia coli is stimulated by culturing cells in the presence of low concentrations of the inhibitor of protein synthesis, lincomycin (Levner et al., 1977; Levner et al., 1980).

In this paper, we report the effect of lincomycin on the production of three secretory proteins of $V$. cholerae-protease II (Young and Broadbent, 1982), one of the secondary virulence factors (Schneider et al., 1981); alkaline phosphatase (Hsieh and Liu, 1970); and deoxyribonuclease

Received 12 Nov. 1984; accepted 4 Mar. 1985.

* Present address: Immunology Research Laboratory, Seattle Public Health Hospital, University of Washington, Seattle 98114 , USA.
(Tsan, 1978) - and we compare this with the effect of the antibiotic on enterotoxin production.

\section{Materials and methods}

\section{Growth of bacteria}

$V$. cholerae El Tor strain 1621 was obtained from Dr J. E. Ogg (Ogg et al., 1978). Bacteria from overnight cultures in Nutrient Broth No. 2 (Oxoid) were inoculated into fresh broth at a dilution of 1 in 100 and grown, with shaking, at $37^{\circ} \mathrm{C}$ for the times specified. Lincomycin hydrochloride (Sigma) was stored as an aqueous solution of $2 \mathrm{~g} / \mathrm{L}$ and added to the growth medium to give the appropriate concentrations. Growth was estimated by measuring the turbidity of samples at $600 \mathrm{~nm}$. Samples were centrifuged in 1-ml volumes in an Eppendorf 5412 centrifuge for $3 \mathrm{~min}$ and supernatant fluids passed through membrane filters $(0.45-\mu \mathrm{m}$ pore size; Millipore). Filtrates were used for enzyme assays and toxin determinations.

\section{Release of periplasmic proteins}

Sodium deoxycholate (BDH) or polymyxin B sulphate (Sigma) was added to cultures to give a final concentration of $1 \mathrm{~g} / \mathrm{L}$ or $2 \mathrm{~g} / \mathrm{L}$ respectively. Cultures were then incubated at $37^{\circ} \mathrm{C}$ without shaking for $15 \mathrm{~min}$ before centrifugation and preparation of filtrates.

\section{Enzyme assays}

Deoxyribonuclease (DNAase) activity was estimated by measuring the amount of acid-soluble material released from ${ }^{3} \mathrm{H}$-labelled DNA. Each $100-\mu \mathrm{l}$ reaction mixture contained Tris- $\mathrm{HCl}$ buffer $(25 \mathrm{~mm}), p \mathrm{H} \mathrm{7.5,}$ $\mathrm{CaCl}_{2}(10 \mathrm{~mm}), \mathrm{MgSO}_{4}(10 \mathrm{~mm}),{ }^{3} \mathrm{H}$-labelled DNA (44 $\mu \mathrm{M})$ and $10 u \mathrm{l}$ of sample filtrate. After incubation for 30 min at $37^{\circ} \mathrm{C}$, the reaction was terminated by adding icecold $\mathrm{HClO}_{4}$ and unlabelled calf-thymus DNA to a final concentration of $5 \% \mathrm{w} / \mathrm{v}$ and $1.25 \mathrm{~g} / \mathrm{L}$ respectively. The assay mixture was kept at $0^{\circ} \mathrm{C}$ for $10 \mathrm{~min}$ before removing 
the acid-precipitable material by centrifugation and estimation of the acid-soluble radioactivity in the supernate by liquid scintillation counting in a toluene: Triton X-100 (2:1) mixture containing butyl PBD $5 \mathrm{~g} / \mathrm{L}$. One unit of enzyme is defined as the amount which releases one nmole of acid-soluble material in $30 \mathrm{~min}$ in these conditions. Release of acid-soluble material was linear with respect to time up to $45 \mathrm{~min}$ and with respect to enzyme concentration up to 4 units.

Alkaline phosphatase (APase) assays were based on the method of Torriani (1960). Reaction mixtures $(0.15 \mathrm{ml})$ contained $p$-nitrophenyl phosphate (BDH) $0.1 \mathrm{mg}, 10 \mathrm{mM}$ Tris- $\mathrm{HCl} p \mathrm{H} 8.0$ and culture filtrate. After $1 \mathrm{~h}$ at $37^{\circ} \mathrm{C}$, reactions were stopped by adding $0.5 \mathrm{M} \mathrm{NaOH}(0.9 \mathrm{ml})$ and absorbance was measured at $400 \mathrm{~nm}$. One unit of enzyme is defined as the amount which hydrolyses $1 \mu$ mole of $p$-nitrophenyl phosphate in $1 \mathrm{~h}$.

Cholera toxin was assayed by the microtitration ganglioside enzyme-linked immunosorbent assay (ELISA) described by Sack et al. (1980). The assay was calibrated with known amounts of purified cholera toxin (Sigma) and a standard curve was obtained for toxin in the region of $1-10 u \mathrm{~g} / \mathrm{L}$. Culture filtrates were assayed in duplicate samples at 5- and 10-fold dilutions.

Protease activity was assayed by a modification of the method of Rinderknecht et al. (1968) described by Young and Broadbent (1982). Reaction mixtures $(1 \cdot 1 \mathrm{ml})$ containing hide powder azure substrate $(17 \mathrm{mg}$ dispensed standard measure), Tris- $\mathrm{HCl}(10 \mathrm{~mm}) \mathrm{pH} 9.0$ and culture filtrate, were used; these conditions provided a measure of the activity of protease II in samples from cultures of $V$. cholerae strain 1621. One unit of enzyme is defined as the amount which results in the solubilisation of $1 \mathrm{mg}$ of hide powder azure in $30 \mathrm{~min}$.

\section{Mutagenesis}

Mutants were obtained by incubating exponentialphase cultures with $\mathrm{N}$-methyl- $\mathrm{N}^{\prime}$-nitro-nitrosoguanidine (NTG, Sigma) $(0.1 \mathrm{mg} / \mathrm{ml})$ for $30 \mathrm{~min}$ at $37^{\circ} \mathrm{C}$ without shaking. After plating, mutant colonies sensitive to lower levels of lincomycin than wild-type strains were detected by replica plating on to nutrient agar with and without lincomycin $50 \mathrm{mg} / \mathrm{L}$.

\section{Results}

\section{Release of periplasmic proteins}

Incubation of cells with sodium deoxycholate (DOC) $0.1 \%$ resulted in the release of DNAase activity from $V$. cholerae (table). In samples removed near the end of the exponential phase of growth ( $7 \mathrm{~h}$ after inoculation) $46 \%$ of the DNAase activity was located in the periplasm compared with $89 \%$ in stationary-phase cultures $(24 \mathrm{~h})$. Alkaline phosphatase activity in the culture supernates was increased 10 -fold by DOC treatment, both in samples obtained during exponential and stationary phases, but the activity of protease II detected in samples from stationary-phase cultures was not increased by this treatment. The presence of DOC in the reaction mixtures at a final concentration of 20 $\mathrm{mg} / \mathrm{L}$ did not affect the activity of the enzymes. The effects of incubation with polymyxin B or DOC were similar for all the enzyme activities tested.

Unless otherwise stated, DNAase and APase activities subsequently described in this paper refer to assays performed on DOC-treated samples while protease and toxin activities were assayed with untreated samples.

\section{Production of enzymes during growth}

The time course for growth of $V$. cholerae and those for the production of DNAase, protease and APase are shown in fig. 1. Protease activity was almost undetectable during the exponential phase of growth but rose rapidly as the culture entered stationary phase. Conversely, APase and DNAase activities were detected both during exponential growth and in the stationary phase. The patterns observed with the latter enzymes differed markedly in that APase continued to rise up to $30 \mathrm{~h}$ after inoculation whereas the total nuclease activity dropped after growth for $24 \mathrm{~h}$.

Table Effect of sodium deoxycholate (DOC) on release of exoenzymes of $V$. cholerae

\begin{tabular}{|c|c|c|c|c|c|c|c|c|c|}
\hline \multirow[b]{2}{*}{$\begin{array}{l}\text { Phase of } \\
\text { growth }\end{array}$} & \multicolumn{3}{|c|}{$\begin{array}{l}\text { APase activity } \\
\text { units } / \mathrm{ml}\end{array}$} & \multicolumn{3}{|c|}{$\begin{array}{l}\text { DNAase activity } \\
\text { units } / \mathrm{ml}\end{array}$} & \multicolumn{3}{|c|}{$\begin{array}{c}\text { protease activity } \\
\text { units } / \mathrm{ml}\end{array}$} \\
\hline & control & $+\mathrm{DOC}$ & $\begin{array}{c}\text { Percentage } \\
\text { released } \\
\text { by DOC }\end{array}$ & control & +DOC & $\begin{array}{l}\text { Percentage } \\
\text { released } \\
\text { by DOC }\end{array}$ & control & $+\mathrm{DOC}$ & $\begin{array}{c}\text { Percentage } \\
\text { released } \\
\text { by DOC }\end{array}$ \\
\hline Exponential & 0.003 & 0.03 & 90 & 3.04 & $5 \cdot 61$ & 46 & 0 & 0 & $\ldots$ \\
\hline Stationary & 0.009 & 0.075 & 88 & 0.64 & $5 \cdot 76$ & 89 & $2 \cdot 6$ & $2 \cdot 3$ & $\cdots$ \\
\hline
\end{tabular}



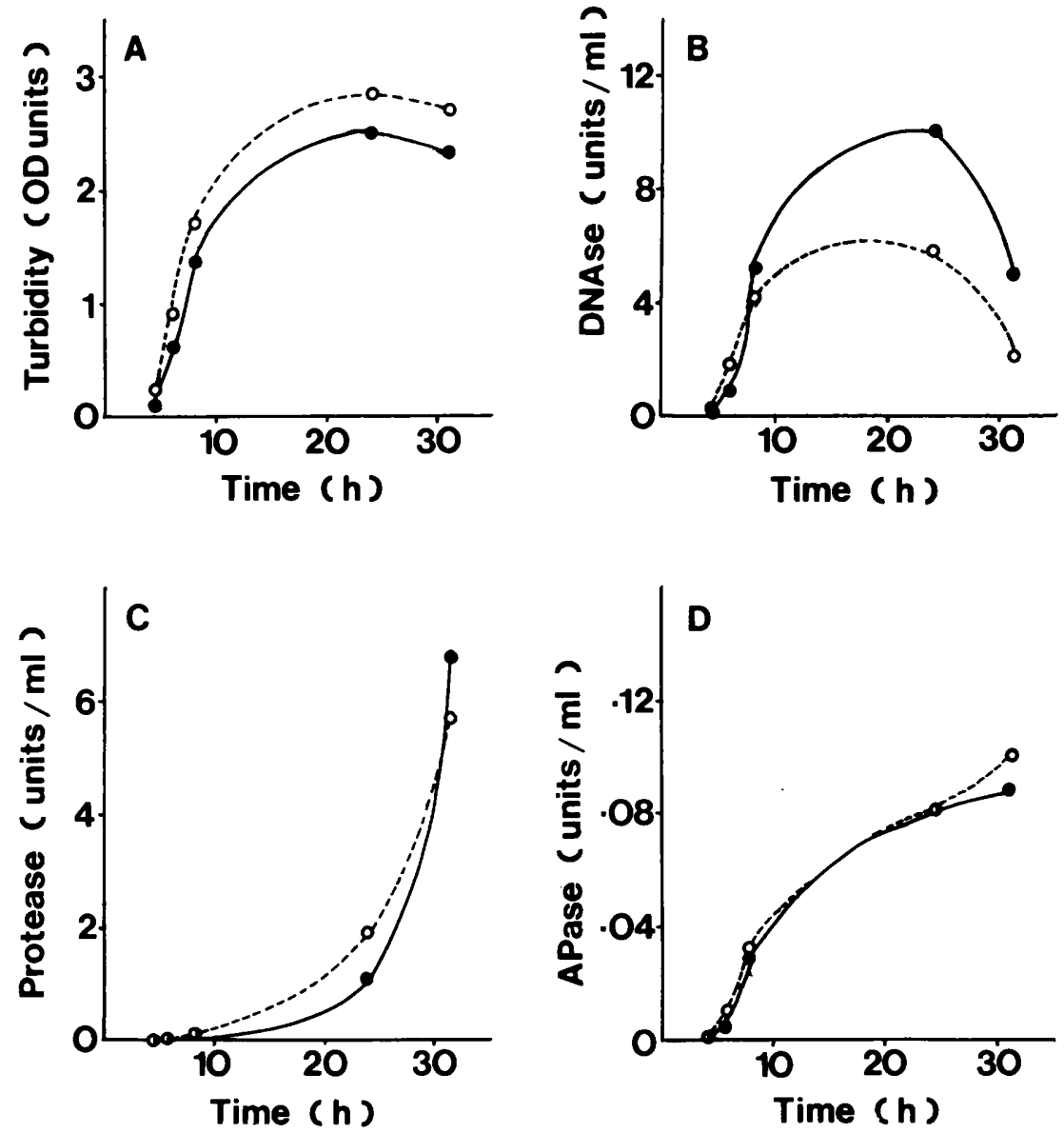

Fig. 1. Time course for exoenzyme production. Samples were removed at various times from cultures of $V$. cholerae growing in the presence $(-)$ and absence (- - - - ) of lincomycin $10 \mathrm{mg} / \mathrm{L}$. Enzyme activities in culture filtrates were assayed as described in the text. A. Growth of cultures as determined by A600; B. DNAase activity after DOC treatment; C. Protease activity; D. APase activity after DOC treatment.

The addition of lincomycin $10 \mathrm{mg} / \mathrm{L}$ had a differential effect on the production of these enzymes. Protease and APase, like growth itself, were only minimally affected both in kinetics and in levels of production. The level of DNAase activity during stationary phase was, however, on average doubled in lincomycin treated cultures. The proportion of activity detected in the DOC-released fractions was similar in control and lincomycin treated cultures $(89 \%$ and $88 \%$, respectively, $31 \mathrm{~h}$ after inoculation).

\section{Effect of lincomycin concentration}

The effect of lincomycin, as assayed in 18-h cultures, was concentration dependent. The antibiotic caused partial inhibition of growth of $V$. cholerae (fig. 2) but resulted in an increase in the relative amount (i.e., amount/A600 unit) of DNAase and toxin (fig. 3). The increase ranged from $0 \cdot 3$-fold at lincomycin $5 \mathrm{mg} / \mathrm{L}$ to approximately 3 -fold at $30 \mathrm{mg} / \mathrm{L}$. This trend was not observed for protease and APase - the relative activities of these enzymes remained constant over the range of lincomycin concentrations examined. When calculated at lincomycin $30 \mathrm{mg} / \mathrm{L}$, the difference between the relative activities of control and antibiotictreated cultures was statistically significant for DNAase and toxin $\left(\mathrm{p}=3 \times 10^{-4}\right.$ and $1.2 \times 10^{-5}$ respectively). Similar comparisons for protease and APase failed to show any significant differences.

\section{Lincomycin-sensitive mutants}

$V$. cholerae strain 1621 grew on nutrient-agar plates containing lincomycin $150 \mathrm{mg} / \mathrm{L}$. Several 


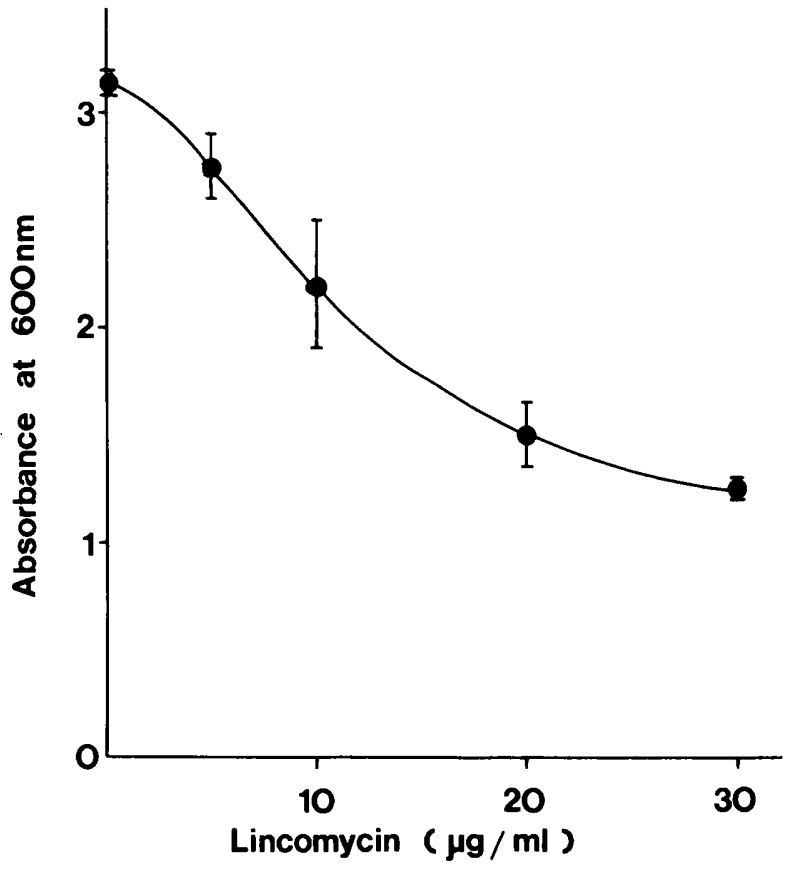

Fig. 2. Effect of lincomycin on the growth of $V$. cholerae. Growth was determined by measuring the absorbance at $600 \mathrm{~nm}$ of cultures $18 \mathrm{~h}$ after inoculation. Points represent mean values from four experiments with standard deviation indicated by the error bars.

mutant strains unable to grow on plates containing lincomycin $50 \mathrm{mg} / \mathrm{L}$ were obtained after NTG mutagenesis. These strains arose at a frequency of $1 /$ $10^{3}$ colonies screened. Mutants showed normal patterns of toxin and exoenzyme production in the absence of the antibiotic. One mutant, which failed to grow on lincomycin $5 \mathrm{mg} / \mathrm{L}$ was selected for more detailed investigation. Growth of this mutant was inhibited by $50 \%$ in the presence of lincomycin 2 $\mathrm{mg} / \mathrm{L}$. Lincomycin $1 \mathrm{mg} / \mathrm{L}$ resulted in the stimulation of the relative amount of DNAase activity $(156 \%$ of control) while relative protease and APase activities were slightly decreased $(83 \%$ and $90 \%$ of control values respectively).

\section{Discussion}

Protease, APase and DNAase represent three different classes of secretory proteins with regard to the effect of sodium deoxycholate and polymyxin $\mathbf{B}$. The amount of protease in culture filtrates was not increased by treatment with DOC or polymyxin, indicating the absence of any pool of active protease in the outer membrane or periplasmic space. Almost all APase activity, on the other hand, remained bound to the bacteria before DOC treatment, suggesting that in $V$. cholerae, as in other

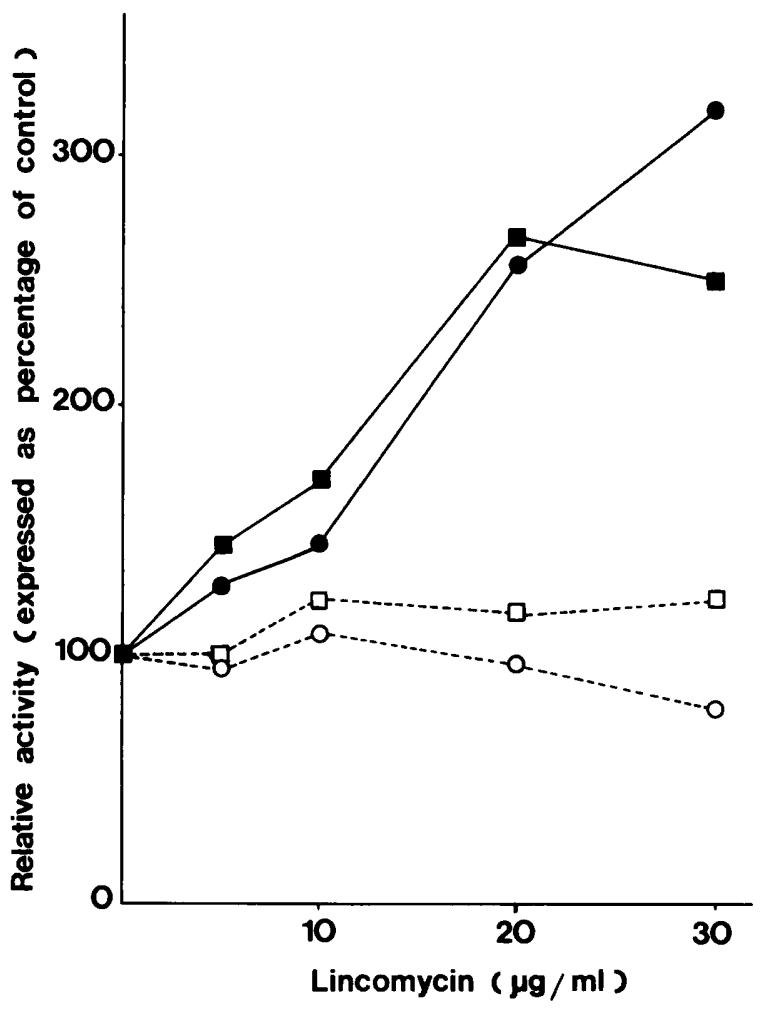

Fig. 3. Effect of lincomycin on exoprotein production. The relative amounts of each exoprotein, i.e., the amount divided by the A600 value, was plotted as a percentage of the control value for different lincomycin concentrations. Each point represents the mean of results from duplicate samples taken from four separate experiments: - - - - DNAase, - - - toxin, - - - - - O- - O- - protease, $-\square--\square--\square--$ APase.

gram-negative species (Costerton et al., 1974), APase is located in the periplasmic space. The DNAase resembles the toxin (Fernandes and Smith, 1977; Levner et al., 1980) in being found both in the extracellular fluid and in the DOC-released fraction. Approximately half of the DNAase activity was free in the supernate during the exponential phase of growth but this proportion declined during the stationary phase. This decline may have been due to the degradation of the enzyme in the supernate by the extracellular protease which is not produced until $10 \mathrm{~h}$ after inoculation.

The stimulation of toxin production by El Tor strain 1621 in the presence of lincomycin is analogous to that previously reported with the classical strain $V$. cholerae 569B (Levner et al., 1980). The effect of lincomycin on DNAase production resembles its effect on the toxin but the relative amounts of protease and APase activities are unaffected by the drug. The DNAase production of lincomycinsensitive mutants resemble the pattern of toxin 
production previously described for lincomycinresistant mutants (Levner et al., 1980) in that a normal lincomycin effect was demonstrated at abnormal lincomycin concentrations.

The mechanism of the lincomycin effect is not yet clear. From the results obtained with toxin in a ganglioside-binding assay, it appears to be an effect on the amount of protein rather than an effect on the biological activity. At low concentrations of lincomycin, where the kinetics of growth and production of protease and APase are only slightly altered, stimulation of toxin and DNAase production occurred. Because lincomycin is a potent inhibitor of protein synthesis, particularly in grampositive bacteria, acting directly on the ribosome (Pestka, 1974), the ribosomes involved in the synthesis of a repressor of toxin and DNAase gene transcription could be extremely sensitive to the antibiotic. The rise in DNAase and enterotoxin activities observed at higher lincomycin concentrations could, perhaps, reflect a lack of antibiotic sensitivity of the ribosomes involved in the synthesis of these proteins relative to ribosomes synthesising the proteins regulating bacterial division. The antibiotic sensitivity of ribosomes synthesising protease and APase would be equivalent to those synthesis-

\section{REFERENCES}

Costerton J W, Ingram J M, Cheng K-J 1974 Structure and function of the cell envelope of gram-negative bacteria. Bacteriological Revien's 38:87-110.

Davis B D, Tai P-C 1980 The mechanism of protein secretion across membranes. Nature 283:433-438.

Evans D J, Evans D G, Gorbach S L 1974 Polymyxin B-induced release of low-molecular-weight, heat-labile enterotoxin from Escherichia coli. Infection and Immunity 10:10101017.

Fernandes P B, Smith H L 1977 The effect of anaerobiosis and bile salts on the growth and toxin production by Vibrio cholerae. Journal of General Microbiology 98:77-86.

Fernandes P B, Bayer M E 1977 Membrane-bound enterotoxin of Vibrio cholerae. Journal of General Microbiology 103: 381-387.

Fernandes P B, Welsh K M, Bayer M E 1979 Characterization of membrane-bound nicotinamide adenine dinucleotide glycohydrolase of Vibrio cholerae. Journal of Biological Chemistry 254:9254-9261.

Hirashima A, Childs G, Inouye M 1973 Differential inhibitory effects of antibiotics on the biosynthesis of envelope proteins of Escherichia coli. Journal of Molecular Biology 79: 373-389.

Holmgren J 1980 Cellular action and pathophysiological effects of cholera toxin. In: Smith H, Skehel J J, Turner M J (eds) The molecular basis of microbial pathogenicity, Verlag Chemie, Weinhelm, pp 269-284.

Honda T, Finkelstein R A 1979 Selection and characteristics of a Vibrio cholerae mutant lacking the A (ADP-ribosylating) portion of the cholera enterotoxin. Proceedings of the National Academy of Sciences of the USA 76:2052-2056.

Hsieh H-C, Liu P V 1970 Serological identities of protease and alkaline phosphatases of the so-called nonagglutinable ing 'division' proteins. Differential antibiotic sensitivity has been described. Thus ribosomes synthesising membrane proteins have previously been shown to be more resistant to puromycin and more sensitive to tetracycline than ribosomes synthesising cytoplasmic proteins (Hirashima et al., 1973). Many proteins destined for export or incorporation into membranes are synthesised on membranebound ribosomes and secreted co-translationally (Davis and Tai, 1980), but it has recently been shown that cholera toxin is synthesised on free ribosomes and secretion is post-translational (Nichols et al., 1980). This observation, together with the present report of a differential effect of the antibiotic on the activities of certain extracellular proteins, suggests that the lincomycin effect does not involve membrane-bound ribosomes but may, alternatively, be specific for synthesis of a particular class of exoproteins for which secretion is posttranslational. It will be of interest to determine whether DNAase secretion is co- or post-translational.

The financial support of the Wellcome Trust is gratefully acknowledged.

(NAG) vibrios and those of Vibrio cholerae. Journal of Infectious Diseases 121:251-259.

Levner M, Wiener F P, Rubin B A 1977 Induction of Escherichia coli and Vibrio cholerae enterotoxins by an inhibitor of protein synthesis. Infection and Immunity 15: 132-137.

Levner M H, Urbano C, Rubin B A 1980 Lincomycin increases synthetic rate and periplasmic pool size for cholera toxin. Journal of Bacteriology 143:441-447.

Nichols J C, Tai P-C, Murphy J R 1980 Cholera toxin is synthesized in precursor form on free polysomes in Vibrio cholerae 569B. Journal of Bacteriology 144:518-523.

Ogg J E, Shrestha M B, Poudayl L 1978 Phage-induced changes in Vibrio cholerae: serotype and biotype conversions. Infection and Immunity 19:231-238.

Pestka S 1974 The use of inhibitors in studies of protein synthesis. Methods in Enzymology 30:261-282.

Rinderknecht H, Geokas M C, Silverman P, Haverback B J 1968 A new ultrasensitive method for the determination of proteolytic activity. Clinica Chimica Acta 21:197-203.

Sack D A, Huda S, Neogi P K B, Daniel R R, Spira W M 1980 Microtiter ganglioside enzyme-linked immunosorbent assay for Vibrio and Escherichia coli heat-labile enterotoxins and antitoxins. Journal of Clinical Microbiology 11:3540.

Schneider D R, Sigel S P, Parker C D 1981 Characterization of Vibrio cholerae protease activities with peptide digest analysis. Journal of Clinical Microbiology 13:80-84.

Torriani A 1960 Influence of inorganic phosphate in the formation of phosphatases by Escherichia coli. Biochimica Biophysica Acta 38:460-469.

Tsan Y C 1978 Nucleic acids hydrolysis by Vibrio cholerae. Chinese Journal of Microbiology 11:114-115.

Young D B, Broadbent D A 1982 Biochemical characterization of extracellular proteases from Vibrio cholerae. Infection and Immunity 37:875-883. 